\title{
Kidney Tumors in Adult: Epidemiological, Clinical, Histopathological, Therapeutic and Progressive Aspects
}

\author{
Modou Ndiaye ${ }^{1}$, Abdoulaye Ndiath ${ }^{1,}$, , Babacar Sine ${ }^{1}$, Alioune Sarr ${ }^{1}$, Ousmane Sow ${ }^{1}$, Omar Gaye ${ }^{2}$, \\ Ndiaga Seck Ndour ${ }^{1}$, Aboubacar Traoré ${ }^{3}$, Cyrille Zé Ondo ${ }^{1}$, Amath Thiam ${ }^{1}$, Ngor Mack Thiam ${ }^{2}$, \\ El Hadji Malick Diaw', Ousmane Dabo ${ }^{2}$, Boubacar Fall ${ }^{3}$, Babacar Diao ${ }^{1}$, Papa Ahmed Fall, \\ Alain Khassim Ndoye ${ }^{1}$
}

${ }^{1}$ Urology-Andrology Department, Aristide Le Dantec Hospital, Dakar, Senegal
${ }^{2}$ Urology-Andrology Department, Idrissa Pouye Hospital, Dakar, Senegal
${ }^{3}$ Urology-Andrology Department, De la Paix Hospital, Ziguinchor, Senegal
${ }^{4}$ Urology-Andrology Department, Dala Diam Hospital, Dakar, Senegal

Email address:

ndiath.ndiath23@gmail.com (A. Ndiath)

${ }^{*}$ Corresponding author

\section{To cite this article:}

Modou Ndiaye, Abdoulaye Ndiath, Babacar Sine, Alioune Sarr, Ousmane Sow, Omar Gaye, Ndiaga Seck Ndour, Aboubacar Traoré, Cyrille Zé Ondo, Amath Thiam, Ngor Mack Thiam, El Hadji Malick Diaw, Ousmane Dabo, Boubacar Fall, Babacar Diao, Papa Ahmed Fall, Alain Khassim Ndoye. Kidney Tumors in Adult: Epidemiological, Clinical, Histopathological, Therapeutic and Progressive Aspects. International Journal of Clinical Urology. Vol. 4, No. 2, 2020, pp. 39-44. doi: 10.11648/j.ijcu.20200402.11

Received: May 6, 2020; Accepted: May 25, 2020; Published: June 8, 2020

\begin{abstract}
Objective: To study the epidemiological, diagnostic and therapeutic profile of kidney tumors in adults over the past five years. Patients and methods: This was a retrospective, descriptive and analytical Study from the $1^{\text {st }}$ of January 2014 to $31^{\text {st }}$ of December 2018. All patients aged 18 years or older hospitalized, followed or operated in the service for a kidney tumor were included in the serie. The parameters studied were: epidemiological, clinical and paraclinical aspects, TNM stage (2017), treatment, histological type, evolution and survival. The calculation of survival rate was done with SPSS IBM statistics 24. Results: sixty-seven patients were included. The average annual incidence was 13. The average age of the patients was $49.6 \pm 15.6$ years. The sex-ratio was 1.2. Hypertension, smoking and obesity were the main risk factors found. The average size of the tumor was $7.7 \pm 4.40 \mathrm{~cm}$. The left kidney location was more frequent. Thirteen patients $(20 \%)$ had a localized tumor in the kidney, twenty patients $(31 \%)$ had locally advanced cancer and thirty two patients (49\%) had metastasized cancer. Forty-seven patients (70\%) had surgical treatment, including five patients with an anti-angiogenic adjuvant therapy. Twelve (17.9\%) patients had an antiangiogenic therapy only. Clear cell carcinoma was the most common histology type. The overall survival (OS) rate for cancer patients at 2 years was $22 \%$ for surgical treatment, $8 \%$ for medical treatment. Conclusion: this work reveals that adult kidney cancer affects young adult and is discovered at advanced stages without any significant change in the epidemiological and clinical profile of these cancers during the two decades.
\end{abstract}

Keywords: Tumor, Cancer, Kidney, Nephrectomy, Anti-angiogenic

\section{Introduction}

The adult's kidney cancer accounts for $3 \%$ of malignant tumors in adults and is the $3^{\text {rd }}$ largest urological cancer after prostate and bladder cancers. [1] It is characterized by a male predominance in $90 \%$ of the cases and is met beyond 50 years in Europe and earlier in Africa [1,2]. Kidney cell carcinoma accounts for $85 \%$ of adult kidney cancer, the majority of which is clear cell carcinoma (75\%) [3]. The diagnosis is made by clinical and radiological arguments, but only histopathological examination of the specimen can confirm the histological nature of the tumor. This sometimes explains the surgical removal of certain benign tumors because the indications for renal biopsy remain limited. 
Therapeutically, radical or partial nephrectomy remains the standard treatment for renal cancer in adults in the localized stage. However, over the last ten years, significant therapeutic advances in the management of kidney cancer have been noted with the development of ablative treatments, partial nephrectomy and especially with the use of targeted therapies in locally advanced and metastatic forms [4]. The objective of this work was to study the epidemiological, diagnostic and therapeutic aspects of kidney tumors in adults over the past 5 years in our center.

\section{Patients and Methods}

This was a retrospective, descriptive and analytical study from $1^{\text {st }}$ January 2014 to $31^{\text {st }}$ December 2018. All patients aged 18 or above hospitalized, followed up or operated in the center for a localized or metastatic kidney tumor were included in our series. The parameters studied were: annual incidence, size, age, sex, risk factors, history, location of the tumor, circumstances of discovery, physical examination, medical imaging (abdominal ultrasound, computed tomography scan, magnetic resonance imaging), tumor stage (TNM 2017) the treatment carried out results, histological type, prognostic factors, growth and survival.

The treatment used was surgical, medical or medicosurgical. Surgical treatment consisted of radical or partial open nephrectomy. Post-operative complications were evaluated according to the classification of Clavien Dindo. The drug used for medical treatment was Sunitinib $50 \mathrm{mg} /$ day for 28 days followed by a 14-day therapeutic window. In case of side effects, the dose was decreased to $25 \mathrm{mg}$. The TNM classification 2017 was used for the TNM classification. The judgment processing criteria were overall survival (OS) according Kaplan-Meier. Data entry and figures and tables were made using Excel 2016 software (Microsoft, Redmond, WA, USA) and the survival curve was made with SPSS IBM statistics 24.

\section{Results}

Sixty-seven patients were included. The annual incidence was higher in 2015 with an annual prevalence to 22 (Figure 1).

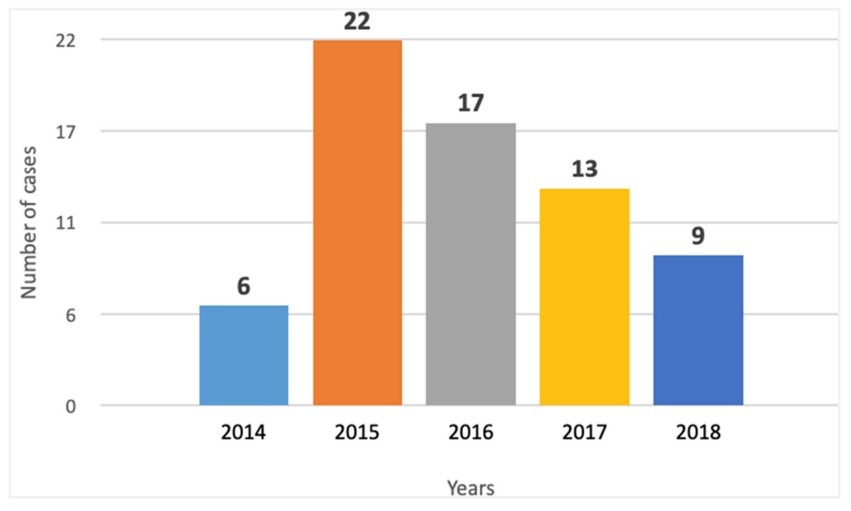

Figure 1. Distribution of patients according to annual incidence $(N=67)$.

The average age was $49.6 \pm 15.6$ years (range $18-81$ years). The sex ratio was 1.6. The most represented age group was between 40 and 49 years old with a rate of $22.4 \%$ (15) of patients.

Twenty-five $(37.3 \%)$ patients had risk factors for kidney cancer. They were arterial hypertension (22.4\%), smoking intoxication (10.4\%) and obesity (4.5\%).

Lumbar pain $(85.1 \%)$ was the most frequent finding followed by lumbar mass $(67.2 \%)$. The classic triad (pain, hematuria and renal mass) was present in $25.4 \%$ (17) of patients. Left kidney was more affected (56.7\%).

Anemia was present in $44.7 \%$ (30) of patients. Impaired renal function was observed in $10.4 \%$ (7) of the patients.

An abdominal CT-scan allowed the diagnosis in 97\% (65) and an ultrasound at 3\% (2) patients. The average size of the tumor was $7.7 \pm 4.4 \mathrm{~cm}$ (range $2-22 \mathrm{~cm}$ ). The characteristics of the tumor on the CT scan were illustrated in Table 1. To complete the staging, $61 \%$ (41) had a chest scan, chest X-ray and a bone scan, made respectively in $61 \%$ (41) $85 \%$ (57) and $3 \%(2)$ patients.

Table 1. Characteristic of the renal tumor objectified on the abdominal CT-scan.

\begin{tabular}{llll}
\hline Characteristics & Types & Number & Percentage \\
\hline Density & Tissue & 55 & $86.1 \%$ \\
& Cystic Bosniak III & 3 & $1.5 \%$ \\
Heterogeneity & Heterogeneous & 55 & $85 \%$ \\
Redesigned with focus of necrosis & & 7 & $10.7 \%$ \\
Calcifications & & 6 & $8.9 \%$ \\
Raising & Peripheral & 65 & $100 \%$ \\
\hline
\end{tabular}

Twenty percent (13) of the patients had localized cancer, 31\% (20) locally advanced cancer and 49\% (32) metastatic cancer.

Fifty-nine (88\%) patients had received treatment. However, eight $(12 \%)$ patients had died before initiating any treatment.

Forty-seven $(70 \%)$ patients had a nephrectomy. It was radical in $95.7 \%$ (45) and partial $4.3 \%$ (2) of these patients.

Fourteen patients had complications from the surgery. According to the Clavien-Dindo classification, these complications were grade II, IIIa and V in 11,1 and 2 patients respectively.
Seventeen patients (25.4\%) had had anti-angiogenic treatment, of which 5 had previously a cytoreductive nephrectomy.

Complications related to anti-angiogenic therapy were: anemia observed in 9 patients, diarrhea in 8 patients, stomatitis in 4 patients, and foot-hand syndrome in 1 patient.

Forty-one $(87.2 \%)$ patients had reported their results of the histopathological examination of the surgical specimen. Clear cell carcinoma was more frequent, objectified in $68 \%$ (28) of patients (Figure 2). 


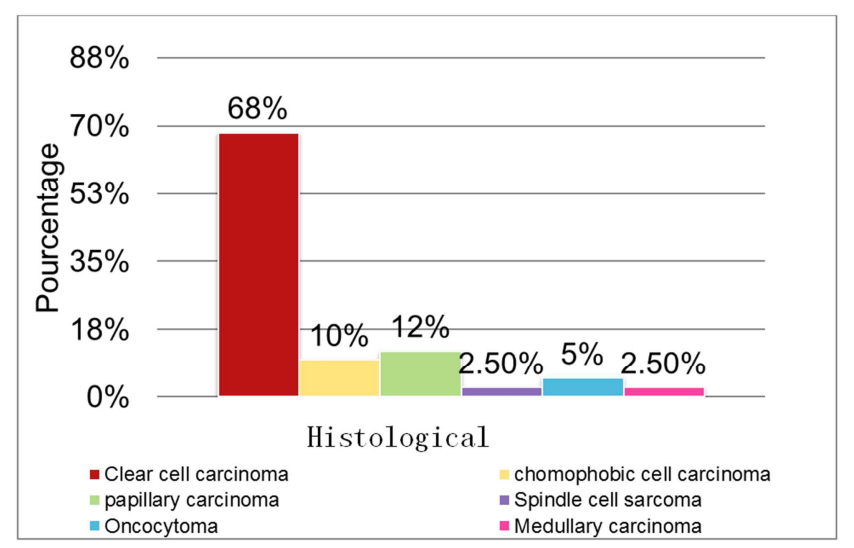

Figure 2. Distribution of histological types according to the percentage of reported results $(N=41)$.

The pTNM classification was specified at $73.2 \%$ (30) of patients. The histological class pT2 was more frequent
(46.6\%). The Fuhrman nuclear grade was noted in $68.3 \%$ (28) of patients. The grade II was more frequent, objectified in $39 \%$ (16) of patients.

After an average follow up time of $2.7 \pm 1.9$ years, $80 \%$ (36) of patients who had a nephrectomy for cancer showed no tumor recurrence. Local recurrence without metastasis, local recurrence of métastases and métastasis without local recurrence were observed in $16 \%$ (7), $2 \%$ (1) and $2 \%$ (1) of these patients, respectively. Twelve patients had stabilized lesions after one or two cycles of Sunitinib. Four patients had a reduction in tumor volume after Sunitinib treatment. One patient had an increase with the appearance of lymph nodes para-aortic and progression of lung and bone metastases lesions.

The OS rate at 6 months was $78 \%$ for surgical treatment; $30 \%$ for medical treatment and $61 \%$ for medical and surgical treatment. At 2 years it was $22 \%$ for surgical treatment and $8 \%$ for medical treatment (Figure 3).

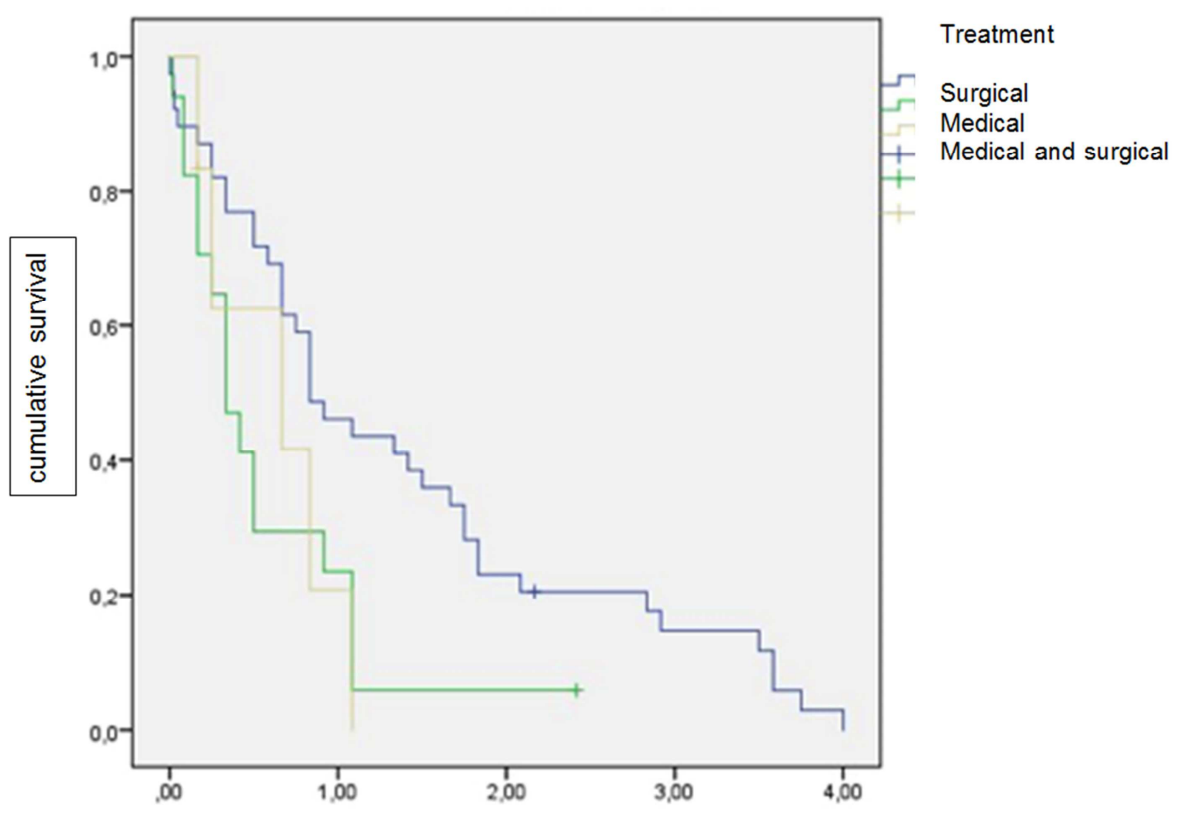

Time (years)

Figure 3. Estimation of survival Kaplan-Meier method different treatments used.

\section{Discussion}

Kidney cancer is the most common type of kidney tumor, it represents $3 \%$ of adult malignant tumors and is the $3 \mathrm{rd}$ most common urological cancer after prostate and bladder cancer [1]. Benign kidney tumors are rare tumors, accounting for about $1 / 5^{\text {th }}$ of all kidney tumors, or $12 \%$ of solid tumors [5]. In our series, sixty-seven patients were collected over a 5 -year period, an annual incidence of 13. An increase in this incidence was noted compared to the incidence of 8.5 found in the series of Fall B et al. [6] in the 2000-2009 decade carried out in the same department as ours. Smaller incidences were found in other African series [7, 8]. The increase in this incidence in our series could be explained by the development of diagnostic means such as CT-Scan in our country. It should also be noted that this incidence of kidney tumors in adults in our series was underestimated, because some records were unusable. The national impact could not be estimated in this series because the study focused only on the exploitation of the files of a single Urology service among many others but also because of the absence of a register cancer research in the country. The difference between Western and African countries in terms of average kidney tumors occurrence of age, first attracts our attention to the potential importance of the racial factor and environment in the development of kidney tumors. However, in the United States, two studies have found no difference in incidence between Caucasian and Black American populations $[9,10]$. Which suggests that environmental risk factors are more likely to explain these differences than genetic parameters. A 
slight male predominance was noted in our series, which has been reported by several African, American and European studies $[6,9,11]$. However, our finding does not reflect the data usually reported in the literature which show a clear predominance of men $[8,12,13]$. The origin of this difference could be sought in terms of lifestyles such as tobacco, the use of which by women currently has considerably increased in our country, or the hormonal interdependence of kidney tumors. Left renal localization is more frequent in renal tumors as shown in several series [9] and then confirmed by ours. Currently, no explanation in the literature has been given to justify this predominance of this more frequent location on the left. The development of radiological investigations has considerably changed the circumstances of diagnosis of kidney tumors. In the literature, kidney tumors are more fortuitous discovery contrary to our results. This discrepancy can be explained by the difficult accessibility to imaging means in our context given the low socio-economic level of our patients. It is the first-line examination because of its safety, availability and lower cost. It is very effective for the study of kidney tumors. This imaging test does not determine with certainty whether a kidney tumor is benign or malignant. However, it does determine the location and the solid or liquid nature of a kidney tumor. Its sensitivity is $85 \%$ in the event of a tumor larger than $3 \mathrm{~cm}$; its specificity is low. Although less sensitive than computed tomography, kidney ultrasound is often the initial examination for screening for renal cystic abnormalities, and is useful in monitoring changes in volume and structure of a preexisting cystic image. In recent years, medicine has benefited enormously from improved diagnostic techniques, especially in terms of imaging. These advances are also felt in our countries, because we had observed a notable difference in this area between the previous decade and the period over which our study extends. In fact, only 19\% of patients from the 1990-1999 decade had an abdominal scanner compared to the $97 \%$ of patients in our series who had had an abdominal scanner. The search for loco-regional, venous, lymph node and metastatic extension of the tumor is also based on renal, abdominal and thoracic CT. The chest CT is superior to the chest X-ray for the detection of pulmonary metastases. It is therefore desirable to request a chest $\mathrm{CT}$ scan before all kidney tumors before surgery or minimally invasive radiofrequency therapy [18]. In developed countries with effective health policy, this difficulty is not in the agenda. MRI appears particularly interesting in the exploration of cystic tumors and small tumors poorly characterized by other imaging examinations. His precise indications need to be defined, its implementation is still reserved for specific cases [14-19]. Locally advanced or metastatic cancers are more frequent in the center as in other African centers Harira et al., [9] unlike Western countries where the cancer is now discovered fortuitously at an early stage [20, 21]. This difference between the two profiles is related to the lengthy consultation period in our country and more widespread and more sophisticated medical imaging use in developed countries. The long consultation period is linked to several factors such as poverty, the remoteness of specialized health facilities and the absence of an adequate social security system.

Radical nephrectomy is the reference of kidney cancer treatment, our observations point in the same direction as the literature data. Radical nephrectomy is indicated both in a radical treatment goal and in the context of a cyto-reduction [22].

The pejorative nature of the venous invasion alone does not explain the poor prognosis but other parameters, such as lymph node involvement and distant metastases, are taken into account. These parameters were significantly higher in patients with venous invasion. Conservative treatment by partial nephrectomy is increasingly indicated today. The rational use of conservative surgery is based on three findings [16, 23].

Patients who had a partial nephrectomy, compared to those with an enlarged nephrectomy, had better long-term renal function [23].

The long-term carcinologic results were identical [16] and $22 \%$ of solid renal tumors less than $4 \mathrm{~cm}$ were benign tumors, A patient with kidney cancer had between 5 to $15 \%$ chance of developing cancer in the contralateral kidney.

This partial nephrectomy can be performed laparoscopically with oncological results that can be superimposed on those of open surgery [24].

The novelty in the treatment of kidney cancer is the use of anti-angiogenic drugs in metastatic kidney cancer. Sunitinib was the only anti-angiogenic molecule used in our series because it is currently the only molecule available to our patients. Treatment with anti-angiogenic has made undeniable progress in the treatment of metastatic kidney cancer but it is not curative and the survival rate at five years is low (10 to 20\%) [25]. However 35 to $45 \%$ of kidney cancers are or will become metastatic. Prevent or delay the on set of metastasis is there fore a major challenge. In over $95 \%$ of cases, surgery remains the first line treatment. The average tumor reduction in patients with an anti-angiogenic treatment in our series was superimposed the results of studies on the anti-angiogenic treatment found tumor reduction between 10 and $20 \%$ [26, 27]. The change in tumor mass can influence the decision in subsequent surgical management of locally advanced kidney cancer. Karakiewicz et al. reported a tumor reduction of 11 to $8 \mathrm{~cm}$ in a patient put on Sunitinib for two months, which made the tumor mass accessible to surgery [28]. Huang et al. [29] suggested that sunitinib acts mainly on endothelial cells rather than by direct targeting of tumor cells, which could explain the low rate of tumor reduction observed in our series.

The JRC show renal tumors in adults for nearly $90 \%$ and some benign tumors such as Oncocytoma and angiomyolipoma. One of the major deficiencies noted in this study was the absence of pathological findings in several patient records. The percentages observed in our study were similar to published data, in fact, the renal cell carcinoma represents $85 \%$ of kidney cancer in adults, the majority of clear cell carcinoma (75\%) while the papillary tumors represent the second most common group of kidney tumors (about 10\%) [3]. This also agrees with the findings of the study on the previous 
decade in Dakar (1990-1999). By comparing our results with that of the series of Khafaja et al. [30]

Abdominal CT-Scan is more effective than ultrasound to detect local recurrence. This recurrence is rare after resection of localized tumors. The risk increases with the size of the tumor, the presence of a positive margin of resection, multifocal tumor or grade [31]. Over $95 \%$ of recurrences occur within the first 5 years of follow-up.

The risk of developing metastases after surgery has been evaluated between 30 and $40 \%$ with a median time of 15 months [32].

The death rate observed in our study was similar to that observed by Fall et al in Senegal with a mortality rate of $47 \%$. [6] All genitourinary cancers, kidney cancer, in particular renal cell carcinoma (RCC), shows the rate of mortality highest [4]. These observations only confirm the derogatory nature of kidney cancer, which is considered to be the most lethal cancer in humans. This lethality could be linked on the one hand to the advanced stage at the time of diagnosis and on the other hand to the high cost of medical treatment with antiangiogenic agents in metastatic forms. In our series, a specific survival rate could not be assessed due to lack of information in the records exploited and the large number of patients lost sight at the time of the study.

\section{Conclusion}

Kidney cancer in adults affects young people and is discovered in advanced stages in our country. There is no significant change in the epidemiological and clinical profile during these two decades. However, the innovations concern the current use of anti-angiogenic agents which have increased survival rates in our series. In our developing countries facing public health problems, it would be necessary to implement health policies facilitating access to healthcare for the poorest people particularly in medical imaging. We must make available and accessible new therapeutic weapons, namely anti-angiogenic seeing their costs and their impact on survival rates.

\section{Conflict of Interest Statement}

All the authors do not have any possible conflicts of interest.

\section{References}

[1] Coulange C, Rambeaud J J. Cancer du rein de l'adulte Rapport-Congrès AFU 1997. Prog Urol 1997; 5.

[2] Honde M, Koffi K, Ette-dieng E, Boka MB, Effi B A, Troh E et al. Aspects épidémiologie et caractéristiques histologies du cancer du rein de l'adulte A ABIDJAN - COTE D'IVOIRE Méd Afr Noire; 1998, 45: 449-450.

[3] Lopez-Beltran A, Scarpelli M, Montironi R, Kirkali Z. WHO classification of the renal tumors of the adults. Eur Urol 2006; 49: 798-805.
[4] Reaume M N, Basappa N S, Wood L, Kapoor A, Bjarnason G A, Blais N, et al. Management of advanced kidney cancer: Canadian Kidney Cancer Forum (CKCF) consensus update 2017. Can Urol Asso Journal. 2017; 11 (10): 310-20.

[5] Skolarus T A, Serrano M F, Grubb R L, Katz M D, Bullock T $\mathrm{L}$ Effect of reclassification on the incidence of benign and malignant renal tumors. J Uro 2010; 183: 455-459

[6] Fall B, Diao B, Sow Y, Sarr A, Thiam A, Fall P A et al. Le cancer du rein de l'adulte au Sénégal: aspects épidémiologiques et cliniques actuels et évolution du profil sur les deux dernières décennies. Prog urol 2011; 21: 521—526.

[7] Bowa K, Kachimba J S, Labib M A, Mudenda V, Chikwenya M. The Pattern of Urological Cancers in Zambia. AFJU. 2009; 15 (2): 84-87.

[8] Benjelloun M, Nouri A, Ghannam Y, Karmouni T, El Khader K, Koutani A et al. Le cancer du rein chez l'adulte. Etude rétrospective à propos de 155 cas. AFJU. 2009; 15 (4): 268-277.

[9] Lynch C F, Cohen M B. Urinary system. Cancer 1995; 75 (1): 316-329.

[10] Muscat J E, Hoffmann D, Wynder E L. The epidemiology of renal cell carcinoma. A second look. Cancer. 1995; 75 (10): 2552-2557.

[11] Black R J, Bray F, Ferlay J, Parkin D M. Cancer incidence and mortality in the European Union: cancer registry data and estimates of national incidence for 1990. Eur J Cancer 1977; 33: 1075-1107.

[12] Ouattara A, Hodonou R, Avakoudjo J, Cisse D, Zango B, Gandaho B et al. Épidémiologie des cancers urologiques au Centre national hospitalier universitaire Hubert Koutoukou Maga Cotonou, Bénin. Analyse d'une série hospitalière de 158 cas. Prog Urol 2012; 22 (5): 261-265.

[13] Soulié M, Coloby P, Irani J, Lebret T, Patard J J, Pfister C et al. Recommandations de bonnes pratiques cliniques $2013 \mathrm{du}$ CCAFU: Diagnostic, traitement et suivi des cancers urologiques chez l'homme et la femme. Prog Urol. 2013; 23 (2): 51-54.

[14] Argani P, Perlman E J, Breslow N E, Browning N E, Green D $\mathrm{M}$, D'Anngio $\mathrm{G} J$ et al. Clear cell sarcoma of the kidney: a review of 351 cases from the National Wilms Tumor Study Group Pathology Centre. Am. J. Surg. Pathol. 2000; 24: 4-18.

[15] Bouya P A, Lomina D. Diagnostic du cancer du rein de l'adulte. Carcinologie Pratique en Afrique 2004; 6 (1): 6-18.

[16] Motzer R J, Hutson T E, Tomczak P, Michaelson M D, Bukowski R M, Rixe O et al. Sunitinib versus interferon alfa in metastatic renal-cell carcinoma. N Engl J Med. 2007; 356 (2): $115-124$.

[17] Flohr H, Breull W. Effect of etafenone on total and regional myocardial blood flow. Arzneimittelforschung. 1975; 25 (9): 1400-1403.

[18] Helenon O, Denys A, Rotkopf L. Imagerie du cancer du rein de l'adulte. Rev Prat 1992; 42: 55-59.

[19] Steiner G, Cairns P, Polascik TJ, Marshall F F, Epstein J I, Sidransky D et al. High-density mapping of chromosomal arm $1 \mathrm{q}$ in renal collecting duct carcinoma: region of minimal deletion at 1q32.1-32.2. Cancer Res. 1996; 56 (21): 50445046 . 
[20] Chow W H, Devesa S S, Warren J L, Fraumeni Jr J F. Rising incidence of renal cell cancer in United States. JAMA 1999; 281 (17): 1628-1631.

[21] Lightfoot N, Conlon M, Kreiger N, Bissett R, Desai M, Warde $P$ et al. Impact of non-invasive imaging on increased incidental detection of renal cell cancer. Eur Urol 2000; 37: 521527.

[22] Bensalah K, Albiges L, Bernhard J C, Bigot P, Bodin T, Boissier R et al. Retracted: Recommandations françaises du Comité de Cancérologie de l'AFU - Actualisation 2018-2020: prise en charge du cancer du rein. Prog Urol. 2018; 28 (12): S3-31.

[23] Lecouteux A, Rigaud J, Glemain P, Le Normand L, Bouchot O, Karam G. Néphrectomie partielle de nécessité pour carcinome à cellules rénales: résultats oncologiques et fonctionnels. Prog urol. 2011; 21: 599-606.

[24] Springer C, Hoda M R, Fajkovic H, Pini G, Mohammed N, Fornara $\mathrm{P}$ et al. Laparoscopic vs open partial nephrectomy for T1 renal tumours: evaluation of long- term oncological and functional outcomes in 340 patients. BJU Int. 2013; 111: 281288.

[25] Miller J C, Pien H H, Sahani D, Sorensen A G, Thrall J H. Imaging angiogenesis: applications and potential for drug development. J Natl Cancer Inst 2005; 97: 172-187.

[26] Rini B I, Garcia J, Elson P, Wood L, Shah S, Stephenson A et al. The Effect of Sunitinib on Primary Renal Cell Carcinoma and Facilitation of Subsequent Surgery. Journal of Urology. 2012; 187 (5): 1548-1554.
[27] Silberstein J L, Millard F, Mehrazin R, Kopp R, Bazzi W, DiBlasio $\mathrm{C} \mathrm{J}$ et al. Feasibility and efficacy of neoadjuvant sunitinib before nephron-sparing surgery: FEASIBILITY AND EFFICACY OF NEOADJUVANT SUNITINIB BEFORE NEPHRON-SPARING SURGERY. BJU International. 2010; 106 (9): 1270-1276.

[28] Karakiewicz P I, Suardi N, Jeldres C, Audet P, Ghosn P, Patard $\mathrm{J} J$ et al. Neoadjuvant Sutent Induction Therapy May Effectively Down-Stage Renal Cell Carcinoma Atrial Thrombi. Eur Urol. 2008; 53 (4): 845848.

[29] Huang D, Ding Y, Li Y, Luo W M, Zhang Z F, Snider J et al. Sunitinib Acts Primarily on Tumor Endothelium rather than Tumor Cells to Inhibit the Growth of Renal Cell Carcinoma. Cancer Research. 2010; 70 (3): 1053-1062.

[30] Khafaja S, Kourie HR, Matar D, Sader-Ghorra C, Kattan J. Kidney Cancer in Lebanon: a Specific Histological Distribution? Asian Pacific Journal of Cancer Prevention. 2015; 16 (1): 363365.

[31] Bernhard J C, Pantuck AJ, Wallerand H, Crepel M, Ferrière J $\mathrm{M}$, Bellec L, et al. Predictive factors foripsi lateral recurrence after nephron-sparing surgery in renal cell carcinoma. Eur Urol 2010; 57: 1080-1086.

[32] Antonelli A, Cozzoli A, Zani D, Zanotelli T, Nicolai M, Cunico SC, et al. The follow-up management of nonmetastatic renal cell carcinoma: definition of a surveillance protocol. BJU Int 2007; 99: 296-300. 